\title{
The effect of shelter availability on the activity of male silver eels*
}

\author{
R. K. EDEL \\ Graduate School of Oceanography, \\ University of Rbode Island, \\ Kingston, Rbode Island, USA
}

KURZFASSUNG: Der Einfluß von Unterschlupfmöglichkeiten auf die Aktivität männlicher Blankaale. Es wird der Nachweis erbracht, daß die Bewegungsaktivität männlicher amerikanischer Blankaale (Anguilla rostrata) durch das Vorhandensein von Unterschlupfmöglichkeiten beeinflußt wird. Zur Messung der Aktivität unter Laborbedingungen diente ein neues Ultraschallverfahren, das gleichzeitig zwei verschiedene Aktivitätsformen registrierte: die Zeitdauer des Aufenthaltes im und die Anzahl der Passagen durch einen Sensortunnel. Durch das Vorhandensein von Unterschlupfmöglichkeiten verringerte sich die pro Tag gemessene Aktivität; die skotokinetische Verhaltensweise der Aale, die sich als deutlich nachtaktiv erwiesen, trat jedoch deutlich hervor. Waren Versteckmöglichkeiten nicht vorhanden, so erhöhte sich die diurnale Gesamtaktivität und der nachtaktive Charakter trat nur noch als eine Störung des mittleren Aktivitätsniveaus hervor. Die mögliche Bedeutung dieser Reaktionen wird diskutiert.

\section{INTRODUCTION}

This paper describes the locomotor activity patterns of male, silver American eels (Anguilla rostrata; LE SUEUR) when shelter was present and absent in a controlled laboratory environment. In addition, a new method for obtaining activity patterns was used which gave two measures of locomotor activity simultaneously.

Few activity studies on fish have taken in account the presence or absence of shelter. Often, when shelter has been varied, only the time relative portion, or phase, of the activity pattern has been analyzed; the levels, or amplitude, of the activity usually were neglected. An exception was the work of HARDEN JONES (1956) on the minnow, Phoxinus, in which he found not only phase reversal but also amplitude reduction when shelter was added.

American eels are generally believed to be nocturnally active and relatively inactive during the daylight period. Unfortunately, little laboratory work has been done on their behavior. BoHUN \& WINN (1966) studied the locomotor activity of American eels but reported that all were juveniles of unknown sex. Because eels in

* This paper will be submitted in partial fulfilment for the degree Doctor of Philosophy in Oceanography at the University of Rhode Island. 
their migratory or silver stage are sexually dimorphic, silver eels $<40 \mathrm{~cm}$ can be assumed to be males (BIEDER, 1971; WINN et al., 1975; VLADYKov, 1973).

Knowledge of the effects of presence or absence of shelter on the activity of silver eels can lead to a better understanding of eel migratory patterns in nature.

\section{MATERIALS AND METHODS}

Male silver eels were selected from the bait-eel supply of a local eel potter. They were caught in baited pots during the summer of 1974 from bradkish rivers in Charlestown and Westerly, Rhode Island, USA, and were probably not quite ready to emigrate to the Sargasso Sea. Eels were held under natural day-night conditions in a large, circular fiberglass reinforced plastic tank with flowing sea water and constant aeration; they were not fed for the duration of the experiment. Only 7 eels were used in the experiments because of time constraints on the facilities. These 7 , averaging $34 \mathrm{~cm}$ in length and $60 \mathrm{~g}$ in weight, were selected from the holding tank one at a time; each was used only once and then preserved.

The test tank was rectangular, fiberglass-reinforced plastic, $148 \mathrm{~cm}$ long, $54 \mathrm{~cm}$ wide and $48 \mathrm{~cm}$ deep installed in a light-tight room at the Marine Experiment Station,

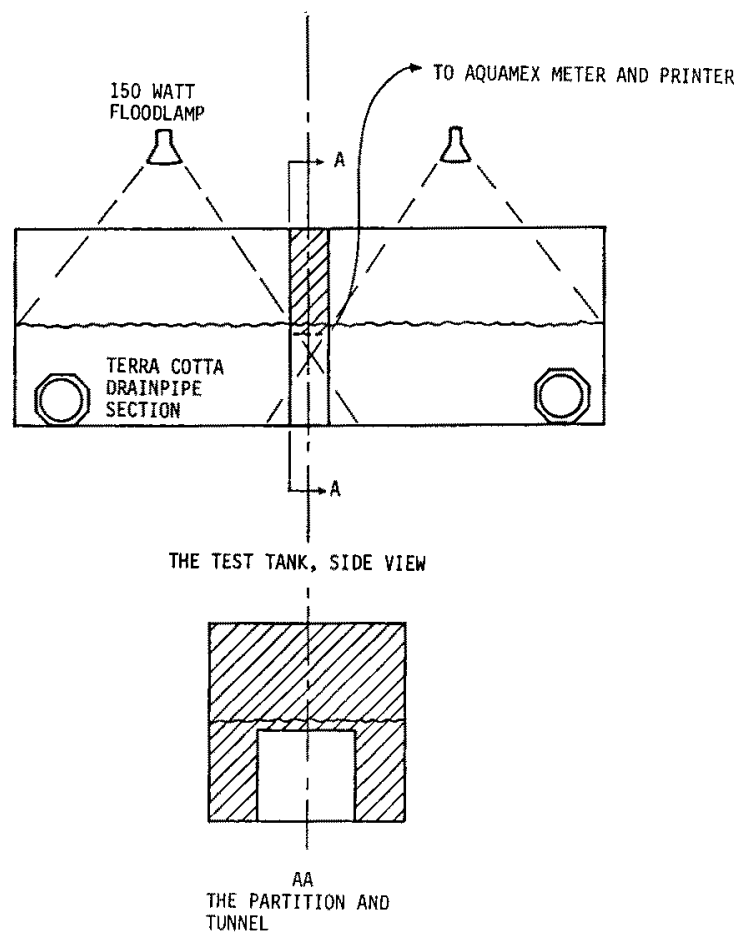

Fig. 1: A schematic diagram of the apparatus showing partition with tunnel and shelter in place 
Jerusalem, Rhode Island. A $3 \mathrm{~cm}$ layer of polyfoam on the walls and ceiling helped to insulate this room from temperature and noise fluctuations. To prevent escape of the eels, water depth in the tank was maintained at only $26 \mathrm{~cm}$. Air was bubbled in behind screens at both ends of the tank. Two $150 \mathrm{~W}$ floodlamps were mounted at equal distances from the ends of the tank. Each was connected through a Variac transformer adjusted so that the light intensity at the water surface directly under the lamp was $1100 \mathrm{mc}$ thereby preventing undesirable heating of the water. A light-dark cycle of $14 \mathrm{~h}$ on $(0600-2000 \mathrm{~h})$ and $10 \mathrm{~h}$ off $(2000-0600 \mathrm{~h})$ was chosen for the experiment.

When shelter was provided, it consisted of 2 terra cotta drainpipe sections $24 \mathrm{~cm}$ long by $12 \mathrm{~cm}$ diameter installed so that each was perpendicular to the long axis of the tank.

The tank was longitudinally divided into 2 symmetrical parts by the installation of an ultrasonic sensing tunnel and associated partition (Fig. 1). Since the sensing tunnel ( $242 \mathrm{~mm}$ high $\times 220 \mathrm{~mm}$ wide $\times 100 \mathrm{~mm}$ deep) was not large enough to cover the cross section of the test tank, a partition was necessary to prevent the eel from getting from one end of the tank to the other without passing through the tunnel. Observations when the sensing tunnel was not switched on showed that eels passed through the tunnel often making "figure-eight" passes through the entire tank. The partition did create one small area of shade which eventually proved to be significant.

The electronics consisted of an Aquamex Activity Meter connected to an Animex Printing Counter from LKB Instruments (division of AB Farad, Stockholm). The sensing tunnel was connected to the meter. Low power, ultrasonic energy was introduced into 1 of 2 matched crystals at opposite corners of the frame. By balancing the input and output signals and using air mirrors to reflect the energy within the tunnel, an invisible wall of sound was formed which was very sensitive to any unbalancing disturbance. Any imbalance caused by the passage of a moving object through the wall of sound would be recorded as a passage and the duration of time the imbalance lasted would be recorded as tunnel residence time. The time interval at which the printing counter would record the sum of passages and tunnel residence times was selected at $1 \mathrm{~h}$. The device would then reset to zero and recycle.

Each trial was begun similarly. The test tank was drained, scrubbed and refilled with sea water matching the holding tank's temperature. Then a test eel was introduced and the tank equilibrated with the air temperature which was continuously monitored. This process took slightly longer than $24 \mathrm{~h}$ so it was decided to analyze the activity record only after temperature became constant. For this reason a test period was defined as a consecutive $48 \mathrm{~h}$ interval including any shelter changes. The temperature was $25 \pm 1^{\circ} \mathrm{C}$ during 6 trials and made one brief excursion to $22.2^{\circ} \mathrm{C}$ during the 7 th trial. Trial 1 began 28 VI 74 and 7 b ended 16 IX 74 .

The passages per hour were calculated as the percent of total tunnel passages for the 48-h-test period. Tunnel residence times were calculated as the percent of each hour spent in the tunnel. 


\section{RESULTS}

The percent total tunnel passes and percent of each hour that an eel spent in the tunnel are graphed in Figure 2 for each of the eight $48 \mathrm{~h}$ trials. In trial 1 shelter was present throughout the 48 -h-test period. The activity pattern was nocturnal with tunnel residence time approximately proportional to passages. For trial 2 shelter was

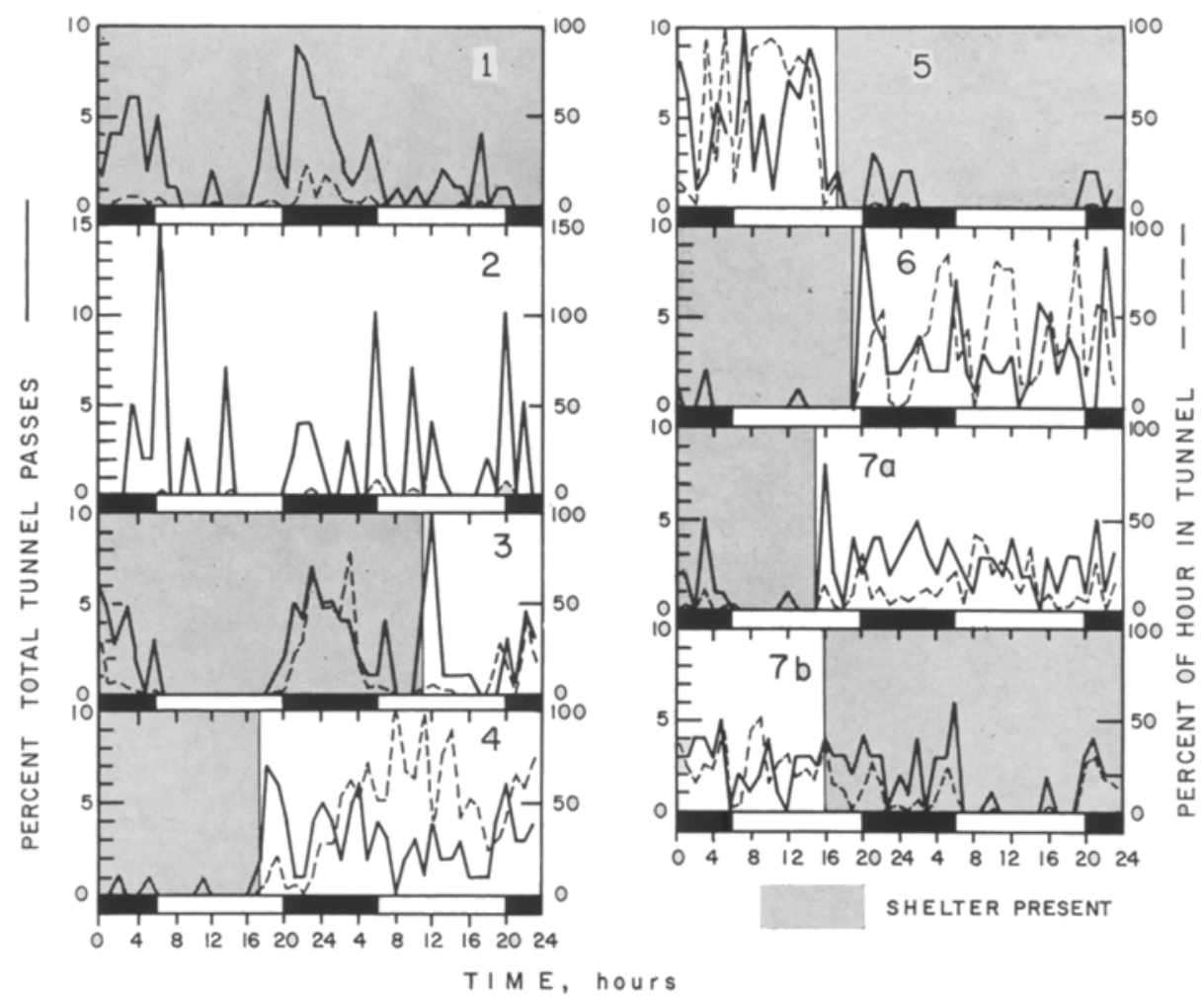

Fig. 2: The activity records of seven male silver American eels determined with an aquamex activity meter. Solid lines represent the percent total tunnel passes. Dashed lines represent the percent of each hour an eel spent in the tunnel. The light-dark cycle is given by the horizontal bar of alternating black and white. The presence of shelter is indicated by the gray shading. Time in hours is given on the abscissa

absent throughout the test period and the activity pattern, which seems quite noisy, was probably crepuscular. This eel had been injured and that could have affected its behavior. Trial 3 began the series of trials in which shelter conditions were altered during the 48 -h-test period. The temporal pattern when shelter was present was nocturnal with little or no activity occurring during the light period. Removal of shelter during the morning of the second day caused a sharp transient of high level passage activity lasting $4 \mathrm{~h}$ during the light period but then decreasing and assuming a 
nocturnal pattern. In trial 4, begun with shelter, there is a suggestion of nocturnalism but the levels are so low it is impossible to be certain. The removal of shelter caused a sharp transient of high level activity during the light period followed by a decline to a lower level even though the dark period had begun. Subsequently, the mean level of activity remained much higher than when shelter was present and a sharply increasing trend to remain in the tunnel expecially during the light phase was clear. For trial 5 the shelter conditions were reversed, i. e. no shelter was present initially but it was added during the test period. With no shelter the mean level of passages and the tunnel residence time (especially during the light phase) were much higher than with shelter. No transient burst of activity was associated with the installation of shelter. Thereafter, a low activity level nocturnal pattern commenced. Trial 6 , which began with shelter present, was a replication of trial 4 . With shelter, very low level nocturnal activity is suggested but not clearly. Removal of shelter caused another transient burst of high level activity followed by dampening. The level of activity thereafter remained higher than when shelter was present. Tunnel residence times did not seem higher during the light phase than during the dark phase. Trial $7 \mathrm{a}$ and $7 \mathrm{~b}$ consisted of the same animal used for 2 consecutive 48 -h-test periods. During the first the animal initially had shelter which was then removed. The low level nocturnal pattern of activity occurred when shelter was present and the removal of shelter caused a burst of transient activity. Without shelter the mean level of activity remained higher than when shelter was present and there was indication of increasing tunnel residence during the light period. In $7 \mathrm{~b}$ the higher mean level is continued as shelter was absent. Reinstallation of shelter did not cause a sharp transient and tunnel residence time can be seen to decline. As the next light period began, the mean activity level was still high but a clear nocturnal rhythm was evident by the end of the trial.

\section{DISCUSSION}

The presence or absence of shelter had a distinct effect on the locomotor activity patterns of male silver eels. When shelter was present eel activity was lower in mean level and highly rhythmic, displaying a nocturnal pattern. When shelter was absent the nocturnal rhythm remained but became a perturbation of a mean activity level which was high during the light period as well as during the dark. Some utilization of the tunnel as a substitute shelter was suggested by the no-shelter parts of trials 4, 5, and 7 a when the tunnel residence times seemed substantially higher during the light periods with a consequent drop in the number of passages but this was not clear in the other cases. The residual nature of the nocturnal rhythm, even though its amplitude could be varied by the presence or absence of shelter, suggests that male silver eels are endogenously scotokinetic - they are always more active in darkness than in light. This agrees with the results of BOHUN \& WINN (1966) who found that young, yellow eels were not only more active nocturnally under an artificial light-dark cycle but also more active under constant dark than under constant light. They tested whether the presence of shelter (sand and gravel for burrowing) had any affect on the locomotor activity patterns in aquaria and con- 
cluded that it did not but they were looking only at the phase relationships of the rhythm and not levels. Because of their percentile treatment of the data between experimental and control animals, all amplitude, or level, information has been lost. The Japanese eel (Anguilla japonica), was reported to be negatively phototactic by KaWAMOTO \& KaBAYASI (1952) but their methods preclude direct comparison with the results obtained here. The habits of the well-studied European eel ( $A$. anguilla) have been covered in extensive reviews prepared by BerTin (1956), Deelder (1970) and TESCH (1973) but no comparable laboratory experiments on activity patterns were mentioned.

The obvious changes in activity levels brought about by the addition or removal of shelter requires consideration of a few points. First, did the method of activity monitoring used - passages through an invisible wall of ultrasonic energy - give true patterns of locomotor activity during the trials? Preliminary observations on the locomotor activity of the eels in the test tank with the Aquamex meter switched on or off showed no differences. The eels generally swam close to the tank bottom proximal to the sides. When the partition was encountered the eels would begin to swim across the tank until they found the tunnel; almost always they would enter the tunnel. When they swam out of the other side of the tunnel they again remained close to the bottom edge, hence a figure-eight swimming pattern was formed. During light periods when shelter was present, an eel would often enter a shelter and remain there for a while. When it left a shelter it would sometimes make a loop on one side of the partition and reenter the same shelter. At other times an eel would pass through the tunnel and enter the shelter on the other side of the partition thereby forming half of a figure-eight. When shelter was absent observations showed that eels would utilize the tunnel as a substitute shelter. Although never as dark inside as the drainpipe shelters the tunnel nevertheless provided a very small area in which an eel would be out of the line-ofsight of either lamp. However, they seemed to move in and out of the tunnel as if sampling the light conditions; hence, there was no $1: 1$ correspondence between tunnel residence time and tunnel passages since only a small part of their bodies had to remain in the tunnel to keep activating the residence time counter but no new passage would be counted. More locomotion was observed when the eels used the tunnel as a substitute shelter than when they used the experimental shelter. Therefore, it is believed that locomotor activity recorded by the Aquamex meter did reflect real differences corresponding to the presence or absence of experimental shelter. It is not likely that eels could detect the ultrasonic energy but no direct evidence is available. The use of the tunnel as a substitute shelter indicates that the eels did not respond negatively to the wall of ultrasound or the scotokinesis is the stronger drive. Again, the preliminary observations with the Aquamex unit switched on and off suggest that ultrasound did not affect the eel's natural behavior. Other methods of detecting locomotor activity have been shown to alter the resultant activity record but there is some evidence that the type of fish being studied determines the extent of the effect. WINN et al. (1975) found activity phase reversals when mechanico-electrical methods were compared to photo-electrical methods but they studied a pelagic and diurnal fish, the alewife. ROBERTS (1963) and WINN (personal communication) found no differences when different monitoring methods were used on catfish and yellow eels, fish normally 
considered to be nocturnal and secretive. The constancy of the low intensity ultrasound used in this study seems to avoid many problems one would incur when using other methods.

It appears, therefore, that male silver eels possess an endogenous behavioral response shown as an increase in activity when shelter is unavailable. It is suggested that an appropriate term for this response is negative sciasmokinesis (from skiasma: shelter, shade); the increase of movement with decreasing shelter availability. Perhaps it resulted from eels' vulnerability to predation in shallow coastal and fresh waters but other possibilities such as avoiding harmful environmental factors or conserving energy exist. Whether this response is unique or redundant to scotokinesis is unknown but interrelation between negative sciasmokinesis and scotokinesis was suggested by the sharp transients of high level activity resulting from the removal of experimental shelter but not from the installation. If the physical act of installing or removing the experimental shelter disturbed the animals, then we would expect to see a transient whenever the test tank was disturbed. Such was not the case. The transient burst only occurred when the experimental shelter was removed, indicating that the eels were searching for shelter; the decline of activity after about $4 \mathrm{~h}$ even though the dark period had started in some instances was impressive. The transients usually reached higher levels than those reached during the remaining $47 \mathrm{~h}$ of most tests.

Further studies are underway to determine where negative sciasmokinesis is no longer important in eel behavior. Male European eels brought to complete maturity through the use of hormone injections still retain an instinct to burrow in laboratory aquaria (Boetius \& Boetius 1967). In nature, however, some environmental conditions such as light, pressure and temperature must trigger an end to shelter seeking. Perhaps when the eels move offshore, beyond the continental shelf, it is as BruUN (1963) suggested: "The eel may find its preferred layer of illumination and migrate continuously day and night."

\section{SUMMARY}

1. The presence or absence of shelter affected the locomotor activity patterns of male silver eels (Anguilla rostrata, Le SUeUR).

2. Whether or not shelter was present, the eels seemed to be more active nocturnally, suggesting endogenous scotokinesis.

3. The presence of shelter depresses total activity obtained during a day while the absence of shelter elevates total activity.

4. Sharp, high-level transients which occurred when shelter was removed but not when shelter was installed were suggestive that shelter availability affects an endogenous behavioral component best called negative sciasmokinesis.

5. The ultrasonic activity meter used for this study yielded 2 measures of activity simultaneously, passage counts and passage time, aiding the recogition of continuing rhythmicity when amplitudes were damped or the record became noisy. 
Adknowledgements. The author was supported by the Office of Naval Research through a grant to Professor H. E. WINN. I thank Professor S. B. SArLA, Director of the Marine Experiment Station, for providing facilities and the use of the Aquamex Activity Meter. Mssrs. D. Sheery and M. Hyman kindly lent assistance. Profs. H. Winn and D. Pratt critically reviewed the manuscript. Dr. F.-W. TEsch kindly translated the abstract.

\section{LITERATURE CITED}

Bertin, L., 1956. Eels - a biological study. Cleaver-Hume, London, 192 pp.

Breder, R. C., 1971. Age and growth in the American eel, Anguilla rostrata (LeSueur), in Rhode Island. Thesis, Univ. Rhode Island, $39 \mathrm{pp}$.

Boetrus, I. \& Boetrus, J., 1967. Studies in the European eel, Anguilla anguilla (L.) experimental induction of the male sexual cycle, its relation to temperature and other factors. Meddr Danm. Fisk.-og Havunders. 4, 339-405.

BoHUn, S. \& WINN, H. E., 1966. Locomotor activity of the American eel (Anguilla rostrata). Chesapeake Sci. 3, 137-147.

Bruun, A. F., 1963. The breeding of the North Atlantic freshwater-eels. Adv. mar. Biol. 1, $137-169$.

Deender, C. L., 1970. Synopsis of biological data on the eel Anguilla anguilla (Linnaeus) 1758. F.A.O. Fish. Synopses 80.

HARden Jones, F. R., 1956. The behaviour of minnows in relation to light intensity. J. exp. Biol. 33, 271-281.

Kawamoto, N. \& Kobayashi, K., 1952. Influence of various light conditions on the gathering rates of fish. Rep. Fac. Fish. prefect. Univ. Mie 1, 139-150.

RoberTs, N. J., 1963. An analysis of the daily activity pattern of the catfish, Ictalurus nebulosus LeSueur. Thesis, Univ. Maryland.

Tesch, F.-W., 1973. Der Aal. Parey, Hamburg, 306 pp.

VlaDykov, V. D., 1973. Macrophthalmia in the American eel (Anguilla rostrata). J. Fish. Res. Bd Can., 30, 689-693.

Winn, H. E., Richкus, W. A. \& Winn, L. K., 1975. Sexual dimorphism and natural movements of the American eel in Rhode Island streams and estuaries. Helgoländer wiss. Meeresunters. 27, 156-166.

Author's address: R. K. EDEL

Graduate School of Oceanography

University of Rhode Island

Kingston, Rhode Island 02881

USA 